\title{
Costs of success: Financial implications of implementation of active learning in introductory physics courses for students and administrators
}

\author{
Eric Brewe \\ Physics Department, School of Education, Drexel University, Philadelphia, Pennsylvania 19104, USA \\ Remy Dou \\ Teaching and Learning, Florida International University, Miami, Florida 33199, USA \\ Robert Shand \\ Department of Educational Studies, The Ohio State University, Columbus, Ohio 43210, USA
}

(Received 5 September 2017; published 9 February 2018)

\begin{abstract}
Although active learning is supported by strong evidence of efficacy in undergraduate science instruction, institutions of higher education have yet to embrace comprehensive change. Costs of transforming instruction are regularly cited as a key factor in not adopting active-learning instructional practices. Some cite that alternative methods to stadium-style, lecture-based education are not financially viable to an academic department. This paper examines that argument by presenting an ingredients approach to estimating costs of two instructional methods used in introductory university physics courses at a large public U.S. university. We use a metric common in educational economics, cost effectiveness (CE), which is the total cost per student passing the class. We then compare the CE of traditional, passive-learning lecture courses to those of a well-studied, active-learning curriculum (Modeling Instruction) as a way of evaluating the claim that active learning is cost prohibitive. Our findings are that the Modeling Instruction approach has a higher cost per passing student $(\mathrm{MI}=1,030 /$ passing student $\mathrm{vs}$ Trad $=790 /$ passing student). These results are discussed from perspectives of university administrators, students, and taxpayers. We consider how MI would need to adapt in order to make the benefits of active learning (particularly higher pass rates and gains on multiple measured student outcomes) available in a cost-neutral setting. This approach aims to provide a methodology to better inform decision makers balancing financial, personnel, and curricular considerations.
\end{abstract}

DOI: 10.1103/PhysRevPhysEducRes.14.010109

\section{INTRODUCTION}

Evidence supports the claim that active-learning approaches to science and math instruction are more effective than traditional lecture instruction. Freeman et al.'s [1] meta-analysis showed that active learning leads to increased conceptual learning and importantly increased odds of success. Even when presented with this evidence, a common defense of lecture is that the financial costs related to transforming science and math instruction are too great. These costs are often associated with smaller classes that create the need for greater numbers of faculty, and physical infrastructure, such as classrooms suitable for active learning [2]. While the costs are undeniably real, estimates of these differences are missing from the literature.

Published by the American Physical Society under the terms of the Creative Commons Attribution 4.0 International license. Further distribution of this work must maintain attribution to the author(s) and the published article's title, journal citation, and DOI.
The question of how to best prepare students has been a central focus of discipline-based education research (DBER) in science fields, and the good news is that we can make significant claims about instructional approaches that promote student learning and success [1,3,4]. For successful implementation of these strategies, undergraduate introductory science classes require significant transformation and universities require significant changes. Yet, university administrators often suggest the payoff does not offset the cost of offering transformed courses as one argument against their availability at institutions of higher education. We explored this line of reasoning by utilizing an ingredients approach to estimating costs of both active learning and lecture-based instructional approaches to introductory university physics courses at a large public U.S. university [5]. In order to compare, we draw on established economic analysis and use a standard metric, cost effectiveness (CE). CE is defined as cost per outcome, so in this analysis we calculate cost per student passing the introductory physics course. We compare the $\mathrm{CE}$ of traditional, passive-learning lecture courses to those of a well-studied, active-learning curriculum 
(Modeling Instruction) as a way of evaluating the claim that active learning is cost prohibitive.

Active learning is an umbrella term and thus there are many variations of active learning that could be evaluated. We have chosen to evaluate Modeling Instruction (MI) for a variety of reasons. First, is that MI has been shown to lead to a number of positive educational outcomes, including improved conceptual understanding and increased odds of success [6] and better attitudes toward learning [7,8]. A survival analysis suggests that students from the MI classes are equally likely to continue in physics as students from lecture classes [9]. Thus, the educational benefits of this active-learning approach are well established and at the same time Modeling Instruction is not widely adopted. MI is emblematic of a class that may be too costly.

At Florida International University (FIU) a small enrollment $(N=30)$ classroom has been used to develop and test curriculum and pedagogy for Modeling Instruction. Modeling Instruction utilizes a studio format for the class, where the lecture and the lab are integrated into one longer class [10]. Simultaneously, FIU also offers fairly typical large lecture $(N=120)$ classes. We consider the CE of offering these two different formats of introductory physics. The MI course, with thirty students, represents an almost polar contrast to lecture-based introductory physics courses often offered at large public research institutions. We acknowledge that different models for course transformation are viable, and other approaches may prove more cost effective; however, this comparison provides maximum contrast and establishes a methodology that can be used to evaluate different approaches to instructional change and the costs associated with them.

\section{LECTURE AND UNIVERSITY MODELING INSTRUCTION}

Lecture continues to be the most common strategy for teaching introductory physics at the university level. The salient characteristics of these types of courses include high student-teacher ratios, students as passive listeners, few solicited student-student or student-lecturer interactions, and stadium-style classroom settings [11]. In contrast to lecture formats are active-learning strategies. Activelearning is characterized by "students being engaged in the process of learning through activities and/or discussion in class... It emphasizes higher order thinking and often involves group work" [1]. Active-learning approaches have been shown in a recent meta-analysis to be more effective at promoting conceptual development, yielding a $0.47 \mathrm{SD}$ improvement over lecture. Importantly, students in lecture courses were found to be $50 \%$ more likely to fail than students in active-learning classes. Freeman et al. [1] concluded that these results were so unambiguous that if this were a medical trial, the trial may have been stopped for benefit, "meaning that enrolling patients in the control condition might be discontinued because the treatment being tested was clearly more beneficial".

Consistent with Freeman et al.'s findings, students in the MI classes at FIU have a higher passing rate ( $88 \%$ in MI vs $52 \%$ in lecture averaged over 11 MI classes and 18 traditional lecture classes from 2004 to 2008, where passing is considered earning a C- or better) [6]. Yet, because of differences in the average number of students enrolled in lecture vs MI, questions arise about the financial viability of the MI approach in spite of its clear educational benefits. The same concern arises when considering the financial impact of similar, active-learning approaches to introductory science courses. Evidence of these costs is often assumed to be understood. We did not find research that estimated the costs of either active learning or lecture approaches or the magnitudes of the differences between these costs.

Differences in pedagogy are accompanied by different infrastructure needs. Lecture classes are typically taught in stadium-style classrooms, with students seated close together. Often seats are fastened to the floor prohibiting rearrangement or reorganization. Further, science, technology, engineering, and mathematics (STEM) classes, like physics, typically include a laboratory component. In lecture settings, a separate lab classroom is needed. Studio format classes [12] such as MI, SCALE-UP [13], or ISLE [14] have different requirements. Studio-format classes are typically designed with flexible use space so that students can use their tables for lab explorations, computer work, or small group activities. Students are often seated in groups to promote discussion and collaboration. Seats are rarely fastened to the ground. Because these classes integrate lab exploration into the "lecture" component of the course, a separate lab classroom is not necessary, but active-learning classrooms typically have a larger footprint per student than lecture classrooms.

\section{COSTS AND QUALITY INSTRUCTION}

In the face of the challenges of understanding and containing costs of higher education, many scholars have noted the importance of reducing costs without sacrificing quality. The National Research Council [15] points out the challenge of defining and measuring quality and productivity without distorting institutional incentives. Wellman [16] warns that increasing enrollments and declining state support put acute emphasis on cost-reducing and qualityincreasing measures: "The collision between student demand and revenues will lead these institutions to reduce access and quality unless they are able to reshape their cost structures." Harris and Goldrick-Rab [17] drew attention to the growing disparity between rising costs and declining degree attainment in higher education. They point out that although enrollments are rising with costs, degree completion is not, meaning that productivity overall in higher education is in decline. They address the concern that there 
may be a fundamental tradeoff between quality and productivity. Universities aiming to contain costs use efforts, such as increasing class sizes and shifting to part-time faculty, which risk reducing quality. Common approaches to increasing quality, such as reducing facultystudent ratios and investing in access and success programs for disadvantaged students, like the federally funded student support service programs in higher education, such as Talent Search and Upward Bound, are very costly.

In investigating various approaches, Harris and Goldrick-Rab [17] argue that the relevant metric is productivity, where productivity is considered to be students completing degrees-not only matriculating. In this view, cost-cutting policies should be pursued if they do not sacrifice quality, and new investments should be considered if they raise quality to a higher standard relative to their costs. Applying these principles some frequently overlooked programs, such as call centers for outreach to students who signal intent to attend classes by registering but who do not attend, show significant promise as ways to enhance productivity. More recent interventions, such as low-cost behavioral nudges to address the problem of "summer melt" [18], hold similar promise to raise productivity by achieving outsize gains in access and quality relative to their costs. The investment by an institution in promoting active learning may be evaluated on the basis of improving productivity.

Other scholars have focused specifically on productivity of institutions, such as community colleges, that serve higher-needs populations of students under significant funding constraints. Jenkins and Rodríguez [19] and Belfield et al. [20] emphasize the importance of using the appropriate economic metric. They define productivity as units of output per units of input, such as graduates per incoming student. This is distinct from efficiency which is units of output per dollar, such as total graduates divided by tuition spent. Belfield et al. [20] in particular examine differences in efficiency between pathways and field. They find that liberal arts fields cost significantly less per completer than allied health fields, even though completion rates are higher in allied health. College-ready students cost less than half as much per completer compared to students who need the most intensive remediation $(\$ 74,000$ vs $\$ 174,400)$. Jenkins and Rodríguez [19] similarly investigate several approaches to increasing productivity and find that using full-time instructors could do so despite the higher cost due to higher completion rates. They also see promise in the area of course redesign, including work by the National Center for Academic Transformation to incorporate technology, labs, and studios into large lecture classes to simultaneously reduce costs and improve outcomes. More recently, the City University of New York has seen promise in increasing the graduation rate in its community colleges using the Accelerated Study in Associate Programs (ASAP) program. Although ASAP is expensive, as a comprehensive network of student supports that increased the cost per student of delivering instruction by $50 \%$, the program also more than doubled the three-year graduation rate, reducing the cost per graduate and providing benefits to taxpayers well in excess of the costs of the program [21].

There is relatively little literature comparing the costs and cost-effectiveness of various methods of instructional delivery with traditional, in-person settings. Brown and Belfield [22], building upon a meta-analysis of experimental studies of lecture compared to other instructional modes by Bligh [23], standardized effect sizes and added costs of instructional time, materials and equipment, facilities, and overhead to compare the cost effectiveness of lectures to personalized instruction, discussion, inquiry, and independent study methods from 38 papers. The results are ultimately ambiguous - there is no method that is consistently more cost effective than lectures. Other methods are more effective but also costlier, and more or less cost effective overall than lectures in roughly equal proportions. Ultimately, then, the decision as to whether to invest in alternative forms of instruction depends upon the willingness to pay for additional output and any financing constraints that institutions face. There have also been some efforts to better understand the costs and cost effectiveness of various forms of delivery of medical instruction, including cataloging the direct and indirect costs of lectures, project-based and small group learning, on-line learning, and clinical instruction, although relatively few conclusions can be drawn due to limited data on both costs and outcomes and lack of agreement on the appropriate selection and measurement of outcomes [24-26]. Finally, Zietz and Cochran [27] examined potentially low- or no-cost ways to raise achievement in economics classes, sidestepping macro issues such as class size and faculty salaries to focus on specific instructional methods. They see potential to increase cost effectiveness through simple strategies, such as assigning additional homework and assessing student learning through a comprehensive final examination.

\section{INGREDIENTS METHOD FOR CALCULATING COSTS}

In order to compare the costs of both traditional physics instruction using a lecture and lab approach, with the integrated Modeling Instruction (MI) approach we used the ingredients method [28]. Using the ingredients method involves first identifying resources that are required for each instructional mode. Identifying the resources involves detailing what it takes for each of the instructional approaches to happen. This includes the personnel, facilities, equipment, and other needs. Once all ingredients have been identified, the costs are then established using market values attempting to account for hidden costs such as use of a classroom in an existing building. The ingredients method 
has two benefits as an approach to estimating the costs associated with achieving a particular effect. First, the method involves tabulating all costs from a resource, or opportunity cost basis, regardless of who pays and whether any financial outlay occurs or a resource is provided in-kind or reallocated from a different purpose. Second, the analysis places emphasis on "what it takes" to achieve a particular outcome, in a particular setting, and under a particular implementation. This analysis is separate from analysis of the total costs from a social perspective, which includes value judgments about expenditures, and from a financing perspective, which considers the distribution of the burden of who pays the costs. The weakness of the ingredients method is that it does not address that universities typically already have classrooms established for traditional lab or lecture instruction in physics, commonly known as sunk costs.

\section{A. Establishing the resources for the ingredients method}

We use data from 2013 because we have published data on student outcomes comparing conceptual gains and odds of success between lecture and MI during this time frame [6] as well as Florida International University's published budget from 2012 to 2013 [29]. Data on implementation were obtained from program documentation, grant application materials describing the facilities and equipment necessary to implement the program, and personal communications with program sponsors. These data were used to estimate quantities and associated prices based on the characteristics of each program ingredient, using prices in 2013 dollars from the Miami metropolitan area.

In this case, the two modes of physics instruction were implemented at FIU. FIU is a large, Hispanic-serving, public institution situated in Miami, FL. As of Fall 2012, 50394 students enrolled at FIU; of these, 36217 were undergraduates. Of all undergraduates, approximately $94 \%$ were registered as "in-state" with regard to tuition. We did not consider fees, such as parking, technology, or lab fees, which are considerable, nor did we include the costs of books. Finally, we also did not consider the role of scholarships, grants, or need-based aid in our calculations.

We relied on a number of assumptions about students enrolled in physics classes, as well. We assumed lecture students enroll in both the four-credit Introductory Physics I course (i.e., PHY 2048) and the separate, one-credit Introductory Physics I laboratory course (i.e., PHY 2048L). Thus, we calculated costs for 5 credits for all students even though some students do not enroll in PHY 2048 and PHY 2048L, simultaneously. We also used 120 students as the standard size of a lecture class; this is fairly typical and was representative of the classes taught during the 2012-2013 academic year. Modeling Instruction courses with 30 students are not supported by graduate assistants.
TABLE I. Instructional effort for teaching introductory physics in both the Modeling Instruction and lecture formats.

\begin{tabular}{|c|c|c|}
\hline Instructor & Lecture & $\begin{array}{l}\text { Modeling } \\
\text { instruction }\end{array}$ \\
\hline $\begin{array}{l}\text { Lecture } \\
\text { component }\end{array}$ & $18 \%$ Faculty effort & $12 \%$ Faculty effort \\
\hline Lab component & $\begin{array}{l}4 \text { Sections of } 30 \text { students } \\
1.33 \mathrm{TAs} / \text { Semester }\end{array}$ & $6 \%$ Faculty effort \\
\hline Grader & $0.25 \mathrm{TA} / \mathrm{Semester}$ & $\cdots$ \\
\hline Total & $\begin{array}{l}18 \% \text { Faculty effort } \\
+1.58 \mathrm{TAs} / \text { Semester }\end{array}$ & $18 \%$ Faculty effort \\
\hline
\end{tabular}

The primary personnel ingredients were physics faculty assisted by graduate students leading lab sections and assisting with grading in the traditional approach (outlined in Table I). Salary data for faculty were estimated using a weighted average of the salaries of physics faculty within each academic rank, weighted by the share of faculty at each rank. Fringe benefits of $31.86 \%$ of salary for faculty and $0.43 \%$ of salary plus a fixed tuition stipend for graduate students based upon rates paid by the university were applied to personnel costs. The 4-credit traditional Physics I lecture plus the 1-credit lab, as well as the 5-credit MI studio course combining both elements, were each assumed to represent approximately $18 \%$ of total faculty effort for the academic year contract, taking into account other teaching responsibilities and the share of time allocated to teaching compared to research and service.

In addition to faculty resources, there are physical infrastructure resources. For this analysis we considered three infrastructure resources: a lecture hall and a lab, which house the lecture instruction approach, a small active-learning classroom, which houses the MI approach. The size of facilities spaces -1465 square feet for a lecture hall, 1945 square feet for a lab, and 1132 square feet for a small MI classroom. New construction prices for classroom and science lab space come from College Planning and Management Magazine annualized over 30 years at a 3.5\% interest rate. The quantities and prices of lab equipment and computers were obtained from a grant proposal application for the MI course, as well as personal communications with physics faculty about lab equipment used for traditional physics courses. Lab equipment was annualized over 10 years and computers over 5 years using the same $3.5 \%$ interest rate. We assumed classrooms were available throughout the academic year, so a 4-credit physics lecture hall used $4.7 \%$ of time (60 hours per semester divided by 1260 hours per year). The MI classroom was specially constructed and used for 9 other classes per semester, so we assumed it was used 5\% of the time for each Physics I class. We assume laptops and lab equipment could be used for four sections of Physics per semester for two semesters per year for a total of $12.5 \%$ of the time for each section of Physics I (traditional or MI). 


\section{B. Economic metrics: Cost effectiveness, incremental costs, yield}

For this analysis the key economic metric that was computed is the cost effectiveness (CE), or the "cost per passing student." Instrumental to this calculation is a definition of passing; we define passing as earning a Cor better to be consistent with Brewe et al. [6]. CE is calculated as the ratio of the average cost per student enrolled in physics instruction in traditional or MI settings to the rate of successful completion of Physics I under each approach. An alternative and equivalent interpretation of the metric is the ratio of the total cost of delivering each instructional approach to a given sample of students to the number of those students who successfully pass Physics I in either case. A higher CE means it costs more per passing student. CE can be used to compare MI to the traditional lecture and lab approach. Since MI has been shown to increase passing rates and is expected to be costlier than traditional physics instruction, we also computed the incremental cost, or the additional cost of providing MI to an equivalent number of students as are served by a traditional physics class. A third metric, yield, is particularly useful from a student perspective. Yield is the inverse of cost effectiveness adjusted to thousands of dollars, number of passing students/1000. Yield is in some ways more intuitive as a lower yield means the instructional mode is less efficient.

\section{RESULTS: COST EFFECTIVENESS}

Table II summarizes the main cost, cost effectiveness, incremental cost, and yield results. The total cost figures are not directly comparable, as traditional physics is delivered to
120 students while MI is delivered to 30 students. However, the share of cost represented by each ingredient is instructive. Personnel comprise the bulk of costs and at similar proportions for traditional physics and MI, although fulltime faculty constitute a much larger share of the costs for MI. MI involves modestly less facilities space (given the smaller, shared space used for both lecture and lab) but significantly greater materials and equipment costs; in some senses, then, it can be seen as substituting technology for facilities space, and full-time faculty for graduate students. Overall, the average cost per student of MI is more than double that of traditional physics, at $\$ 920$ vs $\$ 410$. However, the pass rate for $\mathrm{MI}$ is also significantly higher, meaning that the cost per passing student is modestly higher for MI than traditional physics, at $\$ 1030$ vs $\$ 790$. Modeling Instruction has a $30 \%$ higher cost per passing student than traditional lecture. In the strictest sense, traditional lecture instruction is more cost effective than the MI approach.

\section{A. Incremental costs}

One of the established results from MI (as with other active-learning approaches) is to increase the passing rate for students in Physics I [1,6]. A question relevant to administrators is how much more would it cost to convert to MI. This question is answered by the incremental cost. The incremental costs are the additional costs that would be incurred in teaching the same number of students using MI as with lecture. Delivering MI to four 30-student sections of MI as compared to one large 120 student lecture would cost $\$ 109800$, thus the incremental cost is $\$ 60580$ more than is currently spent. However, we project that 107 students would pass introductory physics on average using four

TABLE II. Costs and cost effectiveness of traditional vs Modeling Instruction physics. Note that prices are adjusted for inflation to 2013, to include fringe benefits for faculty and fringe benefits plus tuition subsidy for graduate students, and annualized at a 3.5\% interest rate over 30, 10, and 5 years, respectively, for facilities, lab equipment, and computers. Passing rates are from Ref. [6]. Cost figures are rounded to the nearest $\$ 10$. Categories are in italics.

\begin{tabular}{|c|c|c|c|c|c|}
\hline \multicolumn{3}{|c|}{ Lecture } & \multicolumn{3}{|c|}{ Modeling instruction } \\
\hline Ingredient & Cost & $\%$ & Ingredient & Cost & $\%$ \\
\hline Personnel & $\$ 41,870$ & 85 & Personnel & $\$ 23,740$ & 86 \\
\hline Physics faculty & $\$ 23,740$ & 48 & Physics faculty & $\$ 23,740$ & 86 \\
\hline Graduate students & $\$ 18,130$ & 37 & $\ldots$ & $\ldots$ & $\ldots$ \\
\hline Facilities & $\$ 6150$ & 12 & Facilities & $\$ 1820$ & 7 \\
\hline Lecture hall & $\$ 2360$ & 5 & MI classroom & $\$ 1820$ & 7 \\
\hline Science laboratory & $\$ 3790$ & 8 & $\ldots$ & $\ldots$ & .. \\
\hline Materials/equipment & $\$ 1200$ & 2 & Materials/equipment & $\$ 1890$ & 7 \\
\hline Lab equipment & $\$ 1200$ & 2 & Lab equipment & $\$ 680$ & 2 \\
\hline$\cdots$ & $\ldots$ & $\cdots$ & Laptops & $\$ 1210$ & 4 \\
\hline Main cost & $\$ 49,220$ & & & $\$ 27,450$ & \\
\hline Number of students & & 120 & & & 30 \\
\hline$<$ Cost per students $>$ & & $\$ 410$ & & & $\$ 920$ \\
\hline$<$ Passing rate $>$ & & 0.52 & & & 0.88 \\
\hline$<$ Number of passing students $>$ & & 62.4 & & & 26.7 \\
\hline$<$ Cost per passing student $>$ & & $\$ 790$ & & & $\$ 1,030$ \\
\hline$<$ Passing students $/ \$ 1000>$ & & 1.27 & & & 0.97 \\
\hline
\end{tabular}


sections of MI as compared with 62.4 in lecture, an increase of $36 \%$ over present rates.

\section{PERSPECTIVES ON ECONOMICS OF COURSE REFORM}

These results raise the question of what an additional student passing introductory physics is "worth" in monetary terms. Additional information is needed in order to compare the investment in MI to alternatives that could also increase course passage rates and ultimately improve student retention and graduation. Information, such as how predictive passing Physics I is for passing future physics courses, persisting in college, selecting a STEM major, and ultimately graduating could help answer this question more fully. Rodriguez et al. [9] provide a survival analysis of students from MI classes suggesting that there are differences in success rates.

\section{A. Departmental perspective}

The main cost, CE, and incremental costs analysis confirmed a common response given by administrators hesitant to offer smaller, active-learning courses. Smaller enrollment courses are in fact more expensive. This is true regardless of considering average cost per student ( $\$ 920$ for MI vs $\$ 410$ for lecture), incremental costs to teach equivalent numbers of students (MI costs $\$ 60,580$ more for 120 students), or cost per passing student ( $\$ 1,030$ for MI vs $\$ 790$ for lecture). From this perspective, the MI courses represent greater costs to the department. A second perspective is the human resources perspective. At Florida International University in 2013 over 1500 students per semester enrolled in introductory physics courses. Requiring 1500 students to be in classes of 30 students would require the department to offer 45 sections of introductory physics. There would not be adequate numbers of faculty to teach this number of courses. Further, scheduling and housing this number of courses would be extremely challenging. Taken together, these two perspectives show that both from a financial and human resource standpoint there are reasons to look for classes larger than 30 students.

From a departmental perspective, larger classes which still maintain higher passing rates are desirable. Larger MI classes could help departments address both the human resource and financial burden due to 30 student classes. A larger enrollment version of MI could make the class more cost effective and may retain additional benefits. Scheduling and staffing would be more feasible. In addition, CE takes into account only the passing rate. Other factors, such as improved conceptual understanding and attitudes toward learning physics, are established outcomes from MI and are not captured by CE. The MI classes also promote the growth of student-student networks [30]. These networks are shown to be predictive of persistence in physics [31] and are theorized to be important to persistence within the university. Drawing on Harris and Goldrick-Rab's [17] recommendations for investment in educational innovations, a scaled-up version of Modeling Instruction could potentially both be cost neutral and provide additional value.

\section{B. Student perspectives}

The Higher Education Opportunity Act (HEOA) [32] requires universities to provide "Student Consumer Information." This framing of students as consumers is a growing component of the higher education economic system and should not be ignored. Students' odds-ofsuccess factors heavily into an economic evaluation of the value of a course. For students, a course's passing rate plays a direct role in their decision to enroll. Their likelihood of having to retake the course can double or triple the final, cumulative tuition cost. Students are naturally inclined to use a cost-value approach that incorporates success rate, asking friends for recommendations or reviewing websites like ratemyprofessors.com.

From students' perspective, MI courses at FIU offer more value. Not only do these courses carry a higher passing rate and therefore a lower effective tuition, but also the level of conceptual knowledge gained and attitudinal improvement is generally greater than what is typically gleaned from a traditional course providing additional value not captured in $\mathrm{CE}$ analyses. Some students may become aware of this through word of mouth. This information may encourage students to take the course that offers more "bang" for their tuition bucks.

Equally consequential, the conceptual and attitudinal gains in MI courses have a strong likelihood of improving student retention and persistence in STEM careers. For some time now, we have known that gatekeeper courses, like introductory physics, negatively influence students' decision to persist in STEM careers, some of which can be attributed to a lack of active engagement with the content and is independent of academic preparation [33,34]. Much research on career persistence in STEM, and physics specifically, must still be done, but what is known about what keeps students in these fields continues to align with the efforts of active-learning advocates [35]. Financial implications should be considered in this work.

\section{Taxpayer perspectives}

New models of funding require universities and university departments to reconsider the value of student achievement. This is noticeable in the K-12 sector through teacher accountability measures tied to salary. State governments are turning to university accountability measures. Florida has adopted a performance-metric system that allocates additional funds based on metrics that tend to relate to measures of student success particularly in introductory courses. These changes behoove those in higher education to consider student success rate in course-cost models. 


\section{DISCUSSION}

The analyses presented here are not universal-they use specific examples of a course transformation, within a specific public institution, within a specific state. However, the analyses provided are a first pass at understanding how the costs of instruction differ and this must be done in specific contexts. The ingredients method use of CE provides a means by which instructional innovations can be compared, but the measure itself is limited. We discuss the limitations of these analyses and how they may be utilized to move toward a more general understanding of the costs and benefits of offering active learning science and mathematics instruction.

\section{A. Instructional constraints}

The analyses presented are specific to the contrasts between a small enrollment Modeling Instruction class and lecture instruction. Modeling Instruction has typically been offered as a 30 student integrated lab and lecture. This format is not common across many universities. We chose MI as a comparison for two primary reasons. The first is that we have strong evidence of the effectiveness of MI as a transformed physics curricula, including pass rates, learning gains, and attitudinal shifts. The second is that MI can be seen as a limiting case, where few transformations represent a greater difference from lecture. Thus, this comparison should represent among the most expensive versions of active learning. To be sure, other versions of active learning exist and may represent greater efficiencies in terms of productivity. In fact, as of 2014 FIU offers larger sections of MI with up to 76 students per class and is maintaining similar academic outcomes as with the smaller sections analyzed here. The assumption we made in our incremental cost analysis was that in order to scale to 120 students we would need four sections of MI. However, with larger sections of MI we would be able to reach 120 students with a lower instructional cost than with four sections. Thus, the value benefits to students and taxpayers as well as the costs to the university would certainly be mitigated by moving to larger versions of active learning courses. Future directions along this line of research would involve comparisons of cost and value for different instructional formats as well as optimization approaches to course size.

In addition, one concern is that a key to our analysis is pass rates, which could be addressed simply through grade inflation or different expectations across the course types. In short, the question, "Are MI classes just lowering expectations?" could explain these differences. The article by Rodriguez et al. [9] confirms that students from MI and lecture are equally likely to complete their degree in physics. We argue this indicates that students are equally prepared for future success and that the pass rates from MI courses are not simply due to lowered expectations.

\section{B. Institutional constraints}

In addition to being specific to MI, these analyses are specific to FIU. Our analyses are based on comparisons between 30 student MI sections with 120 student lecture sections. These course sizes were typical of FIU during this time due to the classrooms available. Course offerings are regularly constrained by the available classrooms. One of the elements that is not addressed in this analysis is the capital contributions needed to design and develop classrooms that can be used for transformed classes like Modeling Instruction. We expect that a comparison of the costs of constructing and maintaining classrooms that accommodate different instruction would be a useful companion to this current analysis.

In addition, FIU is a public institution in Florida. Thus, the analysis includes public contributions to instructional funding. In 2013, the U.S. average revenue coming from state appropriations was $52.5 \%$, and $47.5 \%$ from tuition. This varied from a low of $14.7 \%$ from appropriations in Vermont and a high of $87.0 \%$ in Wyoming [36]. Florida has a relatively high public contribution rate, which makes the taxpayer perspective on efficiency of funding somewhat more relevant. In a state with lower public contribution rates, such as Vermont or New Hampshire, the taxpayer perspective diminishes, but in contrast the student perspective becomes more relevant. Thus, a future direction would be to utilize the ingredients method proposed here in a variety of states and with both public and private institutions to gain a more nuanced perspective on the costs of implementing active learning.

\section{CONCLUSIONS}

For introductory physics courses at FIU, three different stakeholders perspectives create a layered image illustrating the cost and value of MI vs lecture courses. The group with greatest direct benefit from active learning approaches to physics education are students. Students benefit from increased learning and lower likelihood of having to retake the course, which would help them avoid spending additional tuition. Administrators may justifiably claim that MI courses cost more to the department-in terms of both expenditures and human capital; still, this cost may be offset by advantages that result from meeting accountability measures set by the university and the state. While we have utilized a MI course as the basis for this analysis, we contend that extrapolating to other active-learning, evidence-based, reformed STEM courses should be appropriate, including identifying a suitable scale for the size of an MI course which would balance economic pressures with student outcome benefits. Institutional change that incorporates research-based teaching practices cannot occur unless we take into account the various factors that contribute to a school's curricular characteristics, which includes its financial philosophy. 
[1] S. Freeman, S. L. Eddy, M. McDonough, M. K. Smith, N. Okoroafor, H. Jordt, and M. P. Wenderoth, Active learning increases student performance in science, engineering, and mathematics, Proc. Natl. Acad. Sci. U.S.A. 111, 8410 (2014).

[2] A. V. Knaub, K. T. Foote, C. Henderson, M. Dancy, and R. J. Beichner, Get a room: the role of classroom space in sustained implementation of studio style instruction, Int. J. STEM Educ. 3, 8 (2016).

[3] S. R. Singer, Advancing research on undergraduate science learning, J. Res. Sci. Teach. 50, 768 (2013).

[4] N. Kober, Reaching Students What Research Says about Effective Instruction in Undergraduate Science and Engineering (National Academies Press, Washington, DC, 2014).

[5] H. M. Levin, Waiting for godot: Cost-effectiveness analysis in education, New Directions for Evaluation 2001, 55 (2001).

[6] E. Brewe, V. Sawtelle, L. H. Kramer, G. E. O’Brien, I. Rodriguez, and P. Pamelá, Toward equity through participation in Modeling Instruction in introductory university physics, Phys. Rev. ST Phys. Educ. Res. 6, 010106 (2010).

[7] E. Brewe, L. Kramer, and G. O'Brien, Modeling instruction: Positive attitudinal shifts in introductory physics measured with CLASS, Phys. Rev. ST Phys. Educ. Res. 5, 013102 (2009).

[8] E. Brewe, A. Traxler, J. de La Garza, and L. H. Kramer, Extending positive CLASS results across multiple instructors and multiple classes of Modeling Instruction, Phys. Rev. ST Phys. Educ. Res. 9, 020116 (2013).

[9] I. Rodriguez, G. Potvin, and L. H. Kramer, How gender and reformed introductory physics impacts student success in advanced physics courses and continuation in the physics major, Phys. Rev. Phys. Educ. Res. 12, 020118 (2016).

[10] E. Brewe, Modeling theory applied: Modeling Instruction in introductory physics, Am. J. Phys. 76, 1155 (2008).

[11] E. F. Redish, New Models of Physics Instruction Based on Physics Education Research, Proceedings of the Deustchen Physikalischen Gesellschaft (Jena, 1996).

[12] J. M. Wilson, The CUPLE physics studio, Phys. Teach. 32, 518 (1994).

[13] R. J. Beichner and J. M. Saul, Introduction to the SCALE-UP (student-centered activities for large enrollment undergraduate programs) project, Proceedings of the International School of Physics "Enrico Fermi" - Research on Physics Education (IOS Press, Amsterdam, 2003), p. 1.

[14] E. E. Etkina, S. Murthy, and X. Zou, Using introductory labs to engage students in experimental design, Am. J. Phys. 74, 979 (2006).

[15] National Research Council, Discipline-Based Education Research: Understanding and Improving Learning in Undergraduate Science and Engineering, edited by S. R. Singer, N. R. Nielsen, and H. A. Schweingruber (National Academies Press, Committee on the Status, Contributions, and Future Directions of Discipline-Based Education Research; Board on Science Education; Division of Behavioral and Social Sciences and Education; National Research Council, Washington, DC, 2012), pp. 1-231.

[16] J. Wellman, Financial characteristics of broad access public institution, in Stanford Conference on Mapping Broad
Access Higher Education (Stanford Center for Education Policy Analysis, Stanford, 2011).

[17] D. N. Harris and S. Goldrick-Rab, The (un)productivity of American higher education: From cost disease, to cost-effectiveness, in American Education Finance Association (Wisconsin Center for the Advancement of Postsecondary Education, Richmond, VA, 2010).

[18] B. L. Castleman and L. C. Page, Summer Melt: Supporting Low-Income Students Through the Transition to College (Harvard Education Press, Cambridge, MA, 2014).

[19] D. Jenkins and O. Rodríguez, Access and success with less: Improving productivity in broad-access postsecondary institutions, Future of Children 23, 187 (2013).

[20] C. Belfield, P. Crosta, and D. Jenkins, Can community colleges afford to improve completion? measuring the cost and efficiency consequences of reform, Educ. Eval. Policy Anal. 36, 327 (2014).

[21] H. M. Levin and E. Garcia, Accelerating community college graduation rates: A benefit-cost analysis, J. Higher Educ. 89, 1 (2018).

[22] C. Brown and C. Belfield, How cost-effective are lectures? A review of the experimental literature, in Cost-Effectiveness and Educational Policy, edited by H. Levin (Eye On Education, Larchmont, NY, 2002).

[23] D. A. Bligh, What's the Use of Lectures? (Intellect Books, Exeter, 1998).

[24] J. Spencer and J. Pearson, Cost Effectiveness in Medical Education, edited by K. Walsh (Radcliffe Publishing, Oxford, 2010), pp. 48-60.

[25] K. Walsh, Cost effectiveness in medical education: conclusion and next steps, in Cost Effectiveness in Medical Education, edited by K. Walsh (Radcliffe Publishing, Oxford, 2010), pp. 130-134.

[26] K. Walsh, H. M. Levin, P. Jaye, and J. Gazzard, Cost analyses approaches in medical education: There are no simple solutions, Med. Educ. 47, 962 (2013).

[27] J. Zietz and H. H. Cochran, Jr., Containing cost without sacrificing achievement: some evidence from college-level economics classes, Journal of Education Finance 23, 177 (1997).

[28] H. M. Levin, P. J. McEwan, C. R. Blefield, A. Brooks Bowden, and R. Shand, Economic Evaluation in Education: Cost-Effectiveness and Benefit-Cost Analysis, 3rd ed. (Sage Publications, Newbury Park, CA, 2017).

[29] National Science Board, Science and Engineering Indicators 2014 (National Science Foundation, Arlington, VA, 2014).

[30] E. Brewe, L. H. Kramer, and G. E. O'Brien, Changing Participation Through Formation of Student Learning Communities, AIP Conf. Proc. 1289, 85 (2010).

[31] J. P. Zwolak, R. Dou, E. A. Williams, and E. Brewe, Students' network integration as a predictor of persistence in introductory physics courses, Phys. Rev. Phys. Educ. Res. 13, 010113 (2017).

[32] Higher Education Opportunity Act of 2008 (2008).

[33] J. Gainen, Barriers to success in quantitative gatekeeper courses, New Dir. Teach. Learn. 1995, 5 (1995). 
[34] E. Seymour and N. M. Hewitt, Talking About Leaving: Why Undergraduates Leave the Sciences (Westview Press, Boulder, CO, 1997).

[35] G. Crisp, A. Nora, and A. Taggart, Student characteristics, pre-college, college, and environmental factors as predictors of majoring in and earning a STEM degree: An analysis of students attending a Hispanic Serving Institution, Am. Educ. Res. J. 46, 924 (2009).

[36] State Higher Education Executive Officers, State Higher Education Executive Officers, Tech. Rep. (2014). 